\title{
REFLEXÕES SOBRE A FORMAÇÃO DO EDUCADOR MUSICAL DE AGORA
}

\author{
Cristina Tourinho
}

\section{Resumo}

Este artigo reflete sobre as possibilidades de atuação dos licenciados em música e o exercício profissional. Atualmente são demandadas novas formas de atuação, para as quais nenhum currículo pode prever e atender todas as nuances. Então, é preciso refletir acerca do futuro ainda enquanto estudante, exercitando o diálogo, enfrentando desafios e participando ativamente da própria avaliação. Na disciplina "Instrumento Suplementar - Violão" da Escola de Música da UFBA está sendo realizada uma investigação que almeja conscientizar os estudantes acerca da sua trajetória acadêmica e aprendizado instrumental.

\section{Palavras-chave:}

Ensino de Violão; Exercício Profissional; Auto-Avaliação.

Professores de música lidam atualmente com uma realidade bastante distinta de seus colegas de há poucos anos atrás. As gerações estão cada vez mais próximas temporalmente umas das outras, com qualidade de atuação cada vez mais exigente e específica, para a qual não é possível oferecer, durante a graduação, formação que abarque todas as nuances para o futuro exercício da profissão. A quantidade de opções para o exercício profissional se divide em tantas e novas especificidades, incluindo as que envolvem novidades e aparatos tecnológicos, que parece ser impossível acompanhar. A cada dia surge um novo aplicativo, mais um site, uma nova opção com o objetivo de oferecer outras possibilidades para alunos e professores.

No final do século $X X$ ficou reconhecida a neces-

\section{Abstract}

IThis article reflects about the professional practice and performance of undergraduates students and opportunities in music and professional practice. Nowadays new forms of action are demanded, for which any curriculum could anticipate and preview every nuance. So, it is necessary to think about the future as a student, practicing dialogue, facing challenges and actively participating in the self-assessment. In the discipline "Supplementary Instrument - Guitar" of Music Schoolf of Federal University of Bahia is being performed an investigation that aims to educate students about their academic career and instrumental learning.

\section{Keywords:}

Guitar Teaching; Professional Practice; Self-Assessment.

sidade de se estabelecer os saberes que caracterizavam a profissão docente e Maurice Tardif (2008) investigou de que forma os professores lidam com a compreensão dos saberes necessários para o exercício laboral após a graduação. Mesmo reconhecendo que existem vários tipos de saberes, Tardif coloca em destaque os saberes experienciais, isto é, aqueles que são aprendidos e vivenciados durante o exercício da profissão. Diariamente, os professores de música em exercício precisam responder a diferentes estímulos, que muitas vezes não possuem raízes nos ensinamentos recebidos durante o curso que fizeram e que são praticamente impossíveis de se apresentarem da mesma forma e terem a mesma solução. É preciso habilidade, capacidade de improvisação e segurança para decidir o que fazer diante de cada 
problema que surge. Ainda que as situações não se repitam exatamente, muitas vezes, guardam entre si um grau de proximidade que a experiência profissional vai sabendo reconhecer, relacionar e solucionar conforme se apresentam.

Até pouco tempo atrás as profissões estavam bastante definidas, como ainda são denominados e definidos os cursos oferecidos por instituições de ensino superior no Brasil: Bacharelado em Instrumento/Canto, Licenciatura em Música, Composição e Regência, bastando visitar o site www.emec. mec.gov.br para ver a listagem de cursos oferecidos nas instituições públicas e particulares. Os nomes variam um pouco, mas basicamente se referem a estas especificidades. São recentes e numericamente menores os cursos especificamente voltados para "música popular", "música e mídia" e "tecnologia aplicada à música", por exemplo, e para citar apenas alguns. Na prática, as posições de trabalho exigem cada vez mais especificidades para o exercício profissional. Assim, se pensarmos apenas na formação do educador musical do século XXI, esta será distinta de algum tempo atrás em qualidade e quantidade de atuações específicas que podem ser demandadas. Tomando como base o estudo feito por Salazar (2010) e ampliando o lócus do exercício profissional apenas para diferentes tipos de professores, podemos pensar em pessoas que atuem em:

- escolas regulares (públicas e particulares, pré-escolas, ensino fundamental e médio

- conservatórios e escolas de música (públicos e particulares)

- professores de graduação e pós-graduação em música

- projetos sociais

- ensino a distância

- professores particulares

Ainda assim, cada um destes mesmos locais pode exigir uma forma de trabalho diferenciada porque os atores estão em entornos sociais distintos, mesmo que próximos. Dois professores que ensinam em duas escolas diferentes, ambas escolas publicas regulares, à mesma série, mesmo turno, no mesmo bairro, podem enfrentar situações profissionais completamente distintas em vários as- pectos. Seja de quantidade de alunos por turma, portadores de necessidades especiais, infraestrutura, apoio da direção e muitas outras variáveis. Não existe um curso de graduação que possa "preparar" alguém para todos os desafios que vão aparecer no exercício profissional. E também não será possível prever, sem uma pesquisa cuidadosa (Tourinho e Azzi, 2013) que rumos os estudantes darão às suas carreiras. Quem garante que o Licenciado em Música será um professor de música face à diversidade de oportunidades que oferece o mercado de trabalho?

Portanto, pela impossibilidade de prever qual o futuro profissional dos alunos, professores, coordenadores de curso e organizadores de currículos poderiam pensar na formação de músicos que pudessem exercer a profissão com muitas nuances e que fossem profissionais que, mesmo não sendo mais alunos, continuassem aprendizes. São aspectos comportamentais, atitudinais, mas que não deixam de lado o aprendizado musical, que estão sendo explorados em uma disciplina específica, "Instrumento Suplementar - Violão" como vem sendo desenvolvida na Escola de Música da UFBA nos últimos dois anos (Tourinho, 2014).

\section{Referências teóricas: Apoio para a formação do aprendiz}

Toda ação pedagógica está fundamentada teoricamente, ainda que nem sempre os professores sejam capazes de explicitar os autores que guiam suas crenças e nos quais se apoiam. Mesmo "ensinando como aprendeu", o que é comum e natural em boa parte dos recém-graduados, cada um se espelha, inicialmente, nos conhecimentos adquiridos durante o curso, em modelos que inconscientemente admira e em ações já experimentadas anteriormente, sobretudo naquelas que acredita haver solucionado de forma efetiva. Vamos nos referir a alguns deles, da subárea de música e também da psicologia e da educação geral, que servem de suporte para implementar e avaliar as ações realizadas na disciplina "Instrumento Suplementar - Violão" na Escola de Música da UFBA (EMUS). Zabala, (1998, p. 45) fala da "exercitação múltipla", isto é, é preciso repetir muitas vezes a mesma ação para poder aprendê-la e incorporá-la a um repertório pessoal. Mas não basta apenas repetir para aprender, segundo este autor é pre- 
ciso também refletir sobre a própria atividade. 0 convite e o estímulo do professor para a reflexão diminui o caminho, que seria mais longo e disperso caso fossem realizadas apenas repetições mecânicas. Outro fator importante é inclusão de avaliações sistemáticas e formais, que envolvem a participação efetiva do aprendiz e que estabelece uma rotina que permite saber se os objetivos propostos foram alcançados e ajuda a programar novos eventos, a ajustar a disciplina, a procurar atender as necessidades individuais. Em geral se pensa em avaliação como "nota", ou mesmo como "exames" e com a execução de um único ator, o professor. O referencial teórico para avaliação de "Instrumento Suplementar - Violão" se apoia em Luckesi, (2005), Tourinho, (2001) e Swanwick (2003) que recomendam a necessidade de dividir o peso e a responsabilidade da avaliação entre todos os atores do contexto. Assim, o aluno também aprende a refletir sobre sua própria performance e de seus colegas, de forma contínua, saindo da passividade (e muitas vezes, do conforto), de deixar que outros decidam por que caminhos irá trilhar, passando a valorar o processo de aprendizagem e não apenas o resultado final, "passar" ou "reprovar".

Schulman (2005) ressalta que uma das características que distinguem professores experientes de professores iniciantes é que, com o passar do tempo, os primeiros se dão conta das dificuldades dos alunos enquanto que os novatos demoram mais a percebê-las porque estão explorando um terreno pouco conhecido. Podemos inferir, através da experiência, que professores novatos estão extremamente preocupados com o programa escolar, com os conteúdos, em prestar contas de suas atividades aos colegas e à direção e por estes (ou outros motivos) atropelam informações e sentem dificuldades em detectar dificuldades. No ensino formal de música, muitas vezes isto se reflete em escolher um repertório tecnicamente difícil, ansiar "cumprir o programa" e fixar-se apenas nas primeiras camadas do desenvolvimento musical (Swanwick, 2003), dando ênfase à leitura de notas, precisão rítmica, em detrimento da compreensão musical. Nas escolas e conservatórios com programas rígidos e seriados os estudantes têm pouca oportunidade de desenvolver as camadas que propõe Swanwick.

Como último referencial, reportar-nos-emos a
Bandura e a Teoria Social Cognitiva, de forma ampla. A teoria de Albert Bandura é relativamente recente. Em 1986 o autor reuniu suas ideias e investigações renomeando sua teoria como Teoria Social Cognitiva. Esta teoria vem sendo apropriada e usada por diversos segmentos além da educação, como esportes e gerenciamento. Segundo Bandura (2007, p. 15) as pessoas "criam objetivos para si mesmas e preveem os resultados prováveis de atos prospectivos para guiar e motivar seus esforços adequadamente". Aplicado este princípio ao contexto de aprendizagem instrumental, entendemos ser necessário compreender quais são os objetivos dos estudantes e também estimar junto com eles um provável resultado de estudos, tornando-os responsáveis e conscientes da sua produção acadêmica.

A TSC e sua discussão sobre autorregulação da aprendizagem, especialmente a partir do detalhamento encontrado nos estudos de Schunk (2008), nos direciona a pensar sobre as perspectivas do estudante no campo da música. Consideramos que, dentro das escolhas feitas durante o curso de graduação, que está preparando o indivíduo para o seu futuro profissional e ganho de subsistência, as pessoas precisam aprender a planejar as condições para seu aprendizado, estabelecer objetivos pessoais a curto e médio prazo, e também a se autorregular. Isto implica em um posicionamento proativo, bem diferente de um estudante de ensino fundamental e médio, que geralmente adota uma atitude passiva de aprendiz e ainda não está obrigado a fazer escolhas profissionais. Segundo Coimbra (2000), a primeira das grandes escolhas acontece no final do ensino médio, quando se dá o ingresso em um curso de graduação. A partir deste momento, as escolhas que serão feitas vão afetar toda a vida pós universidade.

Entre os objetivos educacionais dos cursos de graduação, a promoção do desenvolvimento da consciência crítica e o estudo consciente do instrumento musical devem desenvolver no aluno o comportamento de constantemente se perguntar para que, por que e como desenvolver atividades que contribuam para a melhoria da sua performance, para o aprendizado de novas peças, para melhoria da leitura a primeira vista, por exemplo. Esta postura frente ao desafio de aprender um novo instrumento ou melhorar a performance dentro de um curso de Licenciatura em Música 
pretende que o aluno evite estudar mecanicamente e sem objetivos definidos, como frequentemente fazem os amadores ou iniciantes.

No senso comum, as escolhas pessoais precisam ser feitas para trazer satisfação e autorealização. Contudo, considera-se que o processo de aprendizagem de um instrumento requer certa dedicação antes que se consigam resultados efetivos. A TSC pode ajudar os professores a pensar em condições de ensino que promovam o desenvolvimento de alunos enquanto agentes de sua própria aprendizagem. Ao considerar que as pessoas podem ser agentes de suas ações, ou seja, atuar com intencionalidade em sua ação, elas se tornam autoinvestigadoras do próprio funcionamento (Bandura, 2007, p. 43).

O papel do professor na promoção de condições que provoquem no aluno o desenvolvimento de agência (expressão de Bandura) nas atividades de aprendizagem da música é crucial, pois precisa proporcionar meios para um estudo consciente e estimulador e que ofereça possibilidades de desenvolvimento para uma aprendizagem autorregulada. Neste sentido, conhecer o aluno, acompanhá-lo em seu processo de aprendizagem e oferecer estratégias de estudo para prática são algumas das condições que devem estar presentes em processos de aprendizagem de instrumentos musicais. A seguir, vamos apresentar algumas informações e estratégias utilizadas na disciplina "Violão, Instrumento Suplementar" a partir do semestre 2013.2, na EMUS-UFBA.

\section{Atividades da disciplina "Instrumento Suple- mentar - Violão: um laboratório para futuros professores}

A disciplina "Instrumento Suplementar Harmônico" é obrigatória para os estudantes do curso de Licenciatura em Música. Eles podem escolher, no currículo recém-aprovado (www.supac.ufba. br) entre piano/teclado e violão, e deverão cursar quatro semestres. Nos últimos dois anos, os alunos matriculados em "Instrumento Suplementar - Violão" já tocavam o instrumento. Todos conhecem cifras e leem música, mas nem sempre sabem fazer leitura aplicada no instrumento. Alguns também tocam guitarra e participam de grupos musicais, se apresentando em shows e festas, de- monstrando muita aptidão para os ritmos da mídia. Apenas $20 \%$ podem tocar uma linha melódica simples e nas primeiras casas do instrumento, porque muitas vezes as peças foram aprendidas vendo/imitando um colega ou vídeo. As peças mais comuns são "Bachianinha" de Paulinho Nogueira, "Romance de Amor" e "Sons de Carrilhões" de João Pernambuco. Estes dados foram recolhidos de um questionário de sondagem preenchido na primeira aula, e que serve de bússola para que o professor planeje o semestre com atividades que atendam ao grupo.

As aulas são coletivas, em grupos de no máximo 4 pessoas por hora. Esta foi outra decisão tomada em virtude da impossibilidade de se constituir turmas com o mesmo nível de habilidade instrumental. O perfil dos estudantes vem se modificando: muitos estudam e trabalham, constituíram família. A própria UFBA divide as aulas entre os dois turnos. Portanto, a alternativa mais efetiva foi sugerir horários e, ao mesmo tempo, permitir que os estudantes escolhessem os mais convenientes.

O programa do semestre inclui tocar duas peças solo, escolhidas de comum acordo entre professor e aluno, uma peça em conjunto, todas com leitura na partitura. Ainda os alunos tocam uma peça em conjunto que inclui, além da leitura, cifras e improvisação. A parte técnica é vista de forma coletiva e, ao mesmo tempo, individual. Exercícios de postura, sonoridade, velocidade, escalas, arpejos, são feitos simultaneamente com todos, respeitando as diferenças, além de aquecimento e relaxamento específicos para a performance instrumental. Também se trabalha leitura a primeira vista, geralmente em peças a duas vozes, tonais e com formas estabelecidas. As discussões em classe são incentivadas, de modo que uns comentem as performances dos outros. Frequentemente 0 professor pede sugestões aos colegas para ajudar, elogiar, sugerir.

A presença em classe é registrada mediante assinatura do aluno a cada aula, em ficha própria. Na mesma ficha, o professor anota, a cada 4 aulas, a sua avaliação acerca do rendimento do estudante, mediante um comentário e nota. Cada estudante faz duas gravações das peças solo em classe. Estas gravações são disponibilizadas individualmente em um link e são comentadas pelo professor, sendo que o estudante deverá responder, por escrito, a três perguntas: como me senti tocando? 
O que posso melhorar em minha performance? O que me agrada em minha própria performance. No final do semestre está marcada uma apresentação pública, em ambiente externo, com programa, cartaz e divulgação na mídia.

\section{Discussão}

O apoio do referencial teórico exposto acima foi fundamental para as decisões tomadas para as atividades em classe. Pode-se relacionar cada uma delas com os autores escolhidos, o que gerou dois quadros distintos. 0 primeiro se refere às percepções do professor da disciplina, preocupado em otimizar o seu trabalho, mantendo-se atento às necessidades e exigências de formação do professor de música enquanto instrumentista.

\begin{tabular}{|l|l|}
\hline Referencial & Atividade \\
\hline Zabala, 1998 "exercitação múltipla" & $\begin{array}{l}\text { Reflexão acerca da própria performance } \\
\text { enquanto professor }\end{array}$ \\
\hline Tourinho e Azzi, 2014 "escolhas profissionais" & $\begin{array}{l}\text { Estimular estudantes no processo decisório } \\
\text { da sua vida acadêmica }\end{array}$ \\
\hline Luchesi & $\begin{array}{l}\text { Programar avaliações processuais, abertas } \\
\text { e comentadas }\end{array}$ \\
\hline Swanwick, 2003 & Não fracionar a avaliação \\
\hline Schulman, 2005 "professores experientes" & Estar atento às dificuldades dos alunos \\
\hline Tardif, 2008 “saberes experienciais" & Aprender com a profissão \\
\hline Bandura (2007) “autorregulação" & $\begin{array}{l}\text { Capacidade de gerenciar seu aprendizado e } \\
\text { comportamento profissional }\end{array}$ \\
\hline
\end{tabular}

Desta forma, o professor é também um ator em constante autoavaliação, usando o próprio referencial teórico de trabalho como apoio para a sua carreira docente.

O segundo quadro contém os mesmos autores, vistos, desta vez, sob a ótica da aplicação para os estudantes. Os mesmos são estimulados a refletir acerca da sua atuação enquanto músicos e futuros professores.

\begin{tabular}{|c|c|}
\hline Referencial & Atividade \\
\hline Zabala, 1998 "exercitação múltipla” & $\begin{array}{l}\text { Reflexão acerca da própria performance enquanto } \\
\text { instrumentista }\end{array}$ \\
\hline Tourinho e Azzi, 2014 "escolhas profissionais" & $\begin{array}{l}\text { Verbalizar e discutir o processo decisório da sua vida } \\
\text { profissional }\end{array}$ \\
\hline Luchesi & $\begin{array}{l}\text { Conhecer, comentar e se posicionar acerca das } \\
\text { avaliações realizadas, recebendo feedback para } \\
\text { melhoria das mesmas }\end{array}$ \\
\hline Swanwick, 2003 & $\begin{array}{l}\text { Estar consciente de que a performance não pode } \\
\text { estar restrita às primeiras camadas do } \\
\text { desenvolvimento musical }\end{array}$ \\
\hline Schulman, 2005 "professores experientes" & $\begin{array}{l}\text { Compreender as dificuldades inerentes à profissão } \\
\text { enquanto instrumentista }\end{array}$ \\
\hline Tardif, 2008 "saberes experienciais" & Aprender com os erros e acertos, \\
\hline Bandura (2008) "autorregulação" & $\begin{array}{l}\text { Capacidade de gerenciar seu aprendizado e compo } \\
\text { tamento profissional }\end{array}$ \\
\hline
\end{tabular}


Existe um constante exercício de aproximar a teoria e a prática, negando a dicotomia que muitas vezes divide a prática enquanto músico da aprendizagem para "ser professor". Assim, em 2014.2 a disciplina será ofertada via Moodle, permitindo que os estudantes tenham acesso a material tanto musical (partituras, cifras) quanto a textos que discutem a formação profissional do ponto de vista da ação enquanto músico-instrumentista. A utilização de meios tecnológicos já está bastante difundida entre os estudantes, embora as classes ainda se perpetuem de forma bastante tradicional, usando partituras e cópias em papel. A utilização do Moodle quer aproximar o manuseio de outras formas de discussão, utilizando textos, fóruns, postagem de arquivos para análise escrita.

Tudo isso sem esquecer que a disciplina se refere á formação técnico-instrumental do futuro professor, porque este vai atuar em classes regulares e, ainda que nem sempre necessite fazer recitais solos, o mesmo deve estar preparado para atuar tocando, seja para organizar apresentações, acompanhar alunos, buscar músicas na internet, transpor e arranjar.

\section{Referências}

BANDURA, Albert. Auto-efficacité. Le sentiment d'efficacité personelle. Traducão de Jacques Lecomte. 2a. Ed. Bruxelas, De Boeck \& Larcier s.a., 2007.

COIMBRA, Susana Maria Gonçalves. Estudo diferencial da auto-eficácia em alunos do 90 ano. Dissertação de Mestrado. Universidade do Porto, 2000, $295 \mathrm{p}$.

LUCKESI, Cipriano Carlos. Avaliação da aprendizagem na escola: reelaborando conceitos e recriando a prática. Salvador, Malabares Comunicações e Eventos, 2005, $2^{\mathrm{a}}$ ed.

SALAZAR, Leonardo. Música Ltda. 0 negócio da música para empreendedores. Recife, SEBRAE, 2010.

SCHULMAN, Lee S. El saber y entender la profesion docente. Estudios Publicos n. 99, 2005, Santiago-Chile, p. 195-224.

SCHUNK, Dale H. Self-Regulated Learning from Teaching to Self-Reflective Practice. New York,
Guilford Press, 2008.

SWANWICK, Keith. Ensinando Música Musicalmente. Trad. Alda Oliveira e Cristina Tourinho. São Paulo, Moderna, 2003.

TARDIF, Maurice. Saberes docentes e formação profissional. Petrópolis, RJ, Vozes, 2008.

TOURINHO, Cristina, AZZI, Roberta. Perspectivas de ingresso no mercado de trabalho por formandos e recém-egressos de cursos de bacharelado em violão. In Trânsito entre Fronteiras na Música. Belém, Editora da UFPA, 2013, p. 95-114.

ZABALA, Antoni. A prática educativa: como ensinar. Porto Alegre, Artmed, 1998.

www.emec.mec.gov.br

www.supac.ufba.br

\section{Sobre a autora}

Cristina Tourinho possui graduação em Instrumento pela Universidade Federal da Bahia (1982), graduação em Professora de Violão pela Universidade Católica do Salvador (1975), mestrado em Música pela Universidade Federa da Bahia (1995) e doutorado em Música pela Universidade Federal da Bahia (2001). É Professor Adjunto da UFBA e foi chefe do Departamento de Música Aplicada (20112005) e Coordenadora do PPGMUS (2009-2012). É professora e orientadora do convênio co-tutelle com a Université de ToulouseLe Mirail, França e professora colaboradora com Hunter College, New York. Colaborou como professor-autor no Curso de Licenciatura em Música a Distância da UFRGS (ProLicen) e na Licenciatura em Música UAB da UnB, bem como nos convênios Minter-Dinter da EMBAP no Paraná e na UFPA. Tem experiência na área de Música, com ênfase em Educação Musical, atuando principalmente nos seguintes temas: vioão, educação musical, avaliação, ensino coletivo de violão e ensino de violão a distância. 